\title{
A Critical Review of Friction Stir Welding Process
}

\author{
VERMA, S. M. \& MISRA, J.P.
}

Abstract: Friction stir welding (FSW) is a permanent type solid state joining process which is increasing rapidly for joining different metal alloys and non-metals in manufacturing industries especially aerospace, marine, spacecraft, automotive, etc. In present scenario the welding of metal alloys are replaced by FSW owing to its unique features over fusion welding processes, i.e. reduced porosity defect, reduced heat affected zone (HAZ), no requirement of shielding gas, ecofriendly, reduced distortion, etc. In this chapter, a critical evaluation of critical aspects of friction stir welding namely process principle, metallurgical and mechanical aspects; effect of preheating and nano-particle inclusion have been discussed. Difficulties and other issues related to FSW are also addressed to provide a guideline to global research community to carry out extensive research in this field.

Key words: Solid-state welding, friction stir welding, preheating, quenching, nanoparticle inclusion
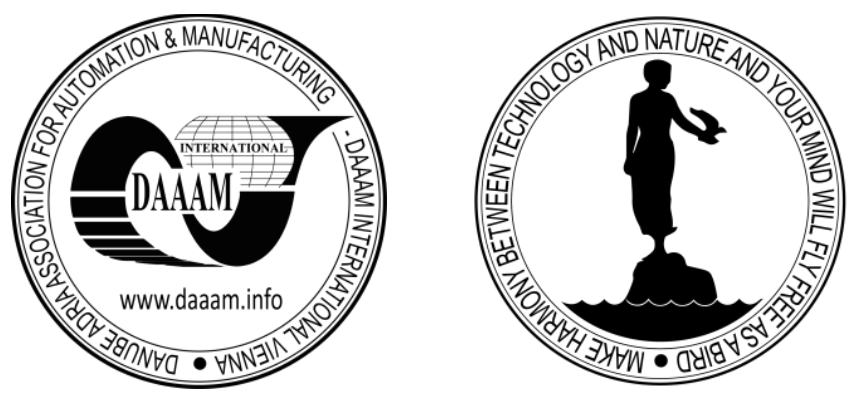

Authors' data: Verma, S[hubham], M[eenu] \& Misra, J[oy] P[rakash], Mechanical Engineering Department, National Institute of Technology Kurukshetra, India, joyprakash.misra@gmail.com.

This Publication has to be referred as: Verma, S[hubham] \& Misra, J[oy Prakash] (2015). A Critical Review of Friction Stir Welding Process, Chapter 22 in DAAAM International Scientific Book 2015, pp.249-266, B. Katalinic (Ed.), Published by DAAAM International, ISBN 978-3-902734-05-1, ISSN 1726-9687, Vienna, Austria DOI: $10.2507 /$ daaam.scibook.2015.22 


\section{Introduction}

In the present scenario joining process industries are growing rapidly in the world of work. The welding came into existence as a viable manufacturing process in the half of $19^{\text {th }}$ century, Messler Jr, (2004); thereafter lots of fusion welding techniques (e.g. arc welding, gas welding) are evolved out. Generally in fusion welding techniques energy density is high and hence heat affected zone is wider and results in solidification defects namely distortion, reduced mechanical properties, lack of penetration, poor fusion rate, etc. In the middle of $20^{\text {th }}$ century plasma arc and laser beam welding techniques are developed capable of producing sound weld of thicker materials with narrow heat affected zone (Lohwasser and Chen, 2010).Though it is found that mechanical properties (e.g. ductility, tensile strength and fatigue strength) are altered at heat affected zone; in addition these techniques are not suitable for reactive elements such as aluminium, magnesium. These drawbacks necessitate the exploration of solid state welding techniques (e.g. resistance welding, friction welding) in which joining occur at a temperature lower than the melting point of base metals without use of filler material or shielding gases. In resistance welding coalescence occurs owing to heat generated by contact resistance and applied pressure and thus, it is not suitable for materials having high electrical conductivity (e.g. copper, aluminium). In Friction welding two pieces are joined by frictional heat generated when a moving workpiece and a fixed component are thrust together in order to obtain the required heat and temperature for weld. The geometry of the workpiece to be joined restricts its application in industries. To overcome the difficulties in welding of especially aluminium and magnesium based alloys by fusion and other welding techniques the welding institute (TWI) invented a unique and novel welding technique named friction stir welding (FSW) after vigorous research in this area. In 1991 Wayne Thomas and his colleagues invented friction stir welding and they realized that joint obtained by the process is $90 \%$ defect free and doesn't melt the workpiece as in case of fusion welding processes (Thomas et al., 1991; Dawes and Thomas, 1995). After the invention of FSW, industries started implementing this technique for fabrication of aluminium components such as hollow aluminium deep freezing panels for ship, fuel tanks for spacecraft, etc. It is found that application of FSW technique in spacecraft manufacturing increases joint strength by $30 \%$ to $50 \%$ and manufacturing time reduces from 23 days to 6 days; cost saving is up to $60 \%$. Thus, its eco-friendly and energy efficient behaviour establish FSW as a green technology (Lohwasser and Chen, 2010).

\subsection{Principle of friction stir welding}

Friction stir welding (FSW) is a solid-state joining technique in which coalescence occurs owing to thermomechanical deformation of workpieces as the resulting temperature exceeds the solidus temperature of workpieces. The fundamental concept of FSW technique is depicted in Figure 1. It consists of a non-consumable rotating tool having a specially designed tool pin and shoulder. Tool pin is plunged into the faying faces of sheets or plates to be joined thus tool moves in the transverse direction along the length. The tool rotates in the clockwise direction and translates from front to back as shown in Figure 1. The left side where the direction of tool rotation is same of tool 
travel direction is termed as advancing side. It is opposite to the direction of metal flow. The side opposite to advancing side where rotation of tool is reverse of direction of tool travel is termed as retreating side. Owing to frictional heat between tool and workpiece, material around the pin is softened and a solid state joint is produced without melting (Backer and Bolmsjo, 2014; Lui et al., 1997; Mishra and Mahoney 2008).

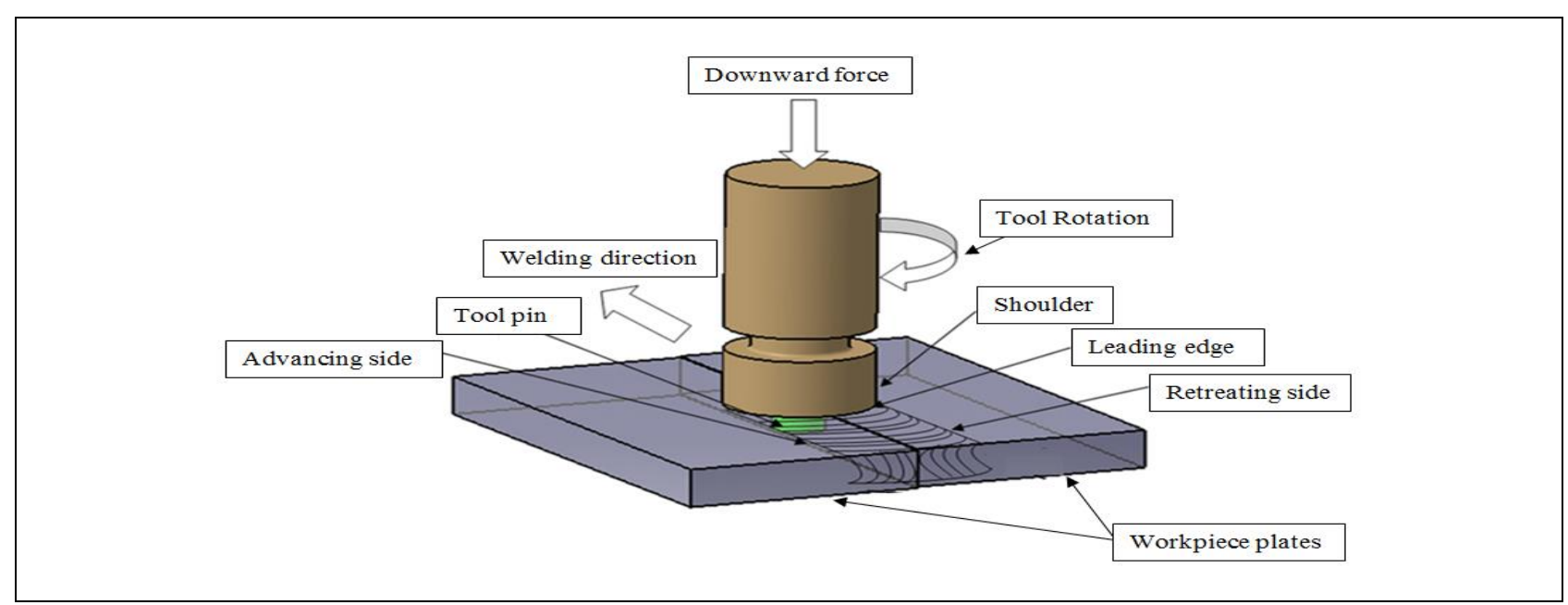

Fig. 1. Principle of friction stir welding (Backer and Bolmsjo, 2014)

In FSW joints various microstructural regions can be observed as illustrated in Figure 2. The parent metal region is unaffected by heat as it is far away from the recrystallized zone and hence microstructural and mechanical properties of this region remains unaltered. The second region is heat-affected zone that is next to parent metal and is affected by heat but no plastic deformation takes place in this region; however, mechanical and microstructural property changes. The next region is thermomechanically affected zone that is very near to weld nugget and it is plastically deformed by means of tool. In this region material deforms without recrystallization. Next region is nugget zone or stir zone or fully recrystallized zone in which tool pin rotates and produces frictional heat; results in severe plastic deformation (Mahoney et al., 1998; McNelley et al., 2008).

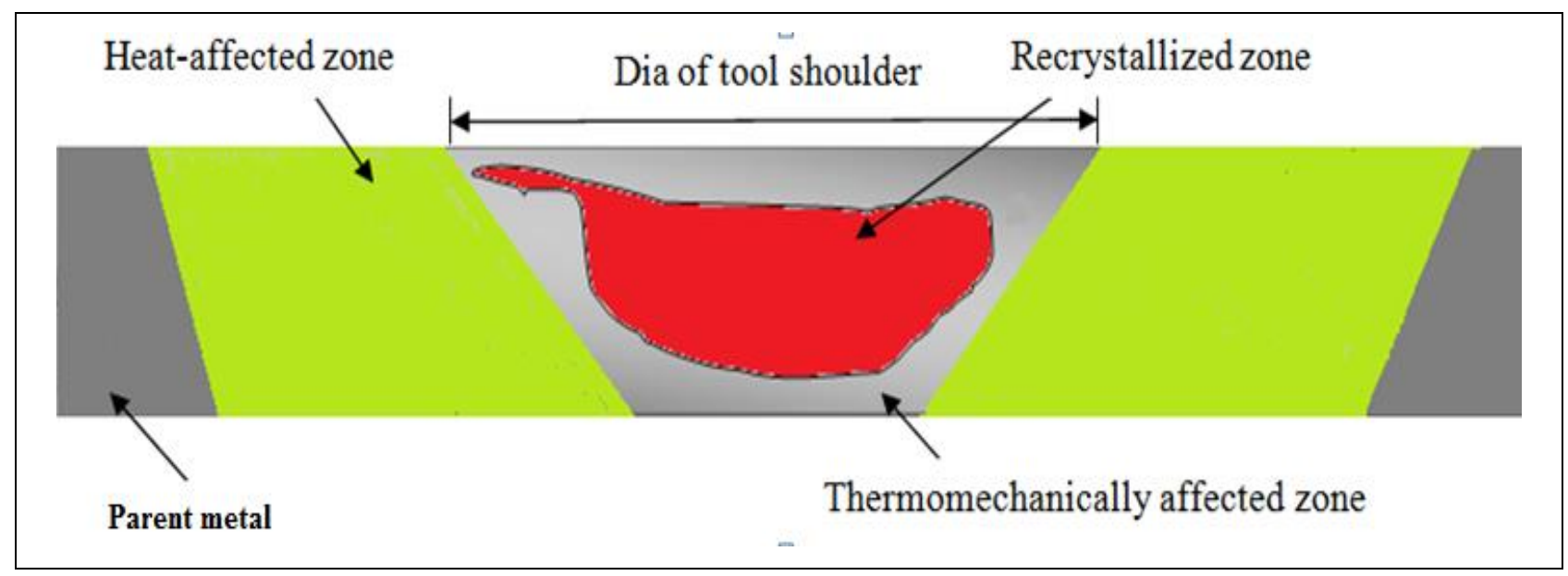

Fig. 2. Microstructural regions of friction stir welding (Mahoney et al., 1998) 


\subsection{Process parameters}

The process parameters for friction stir welding are broadly classified into three groups: (a) tooling related parameters: shoulder and pin material, shoulder diameter, pin length, pin diameter, feature geometry, thread pitch, etc.; (b) machine related parameters: welding speed, plunge force or depth, spindle speed, tool tilt angle, etc.; and (c) other parameters: anvil material, anvil size, workpiece size, workpiece properties, etc. (Lohwasser and Chen, 2010). The influencing process parameters are illustrated using a cause-effect diagram in Fig. 3.

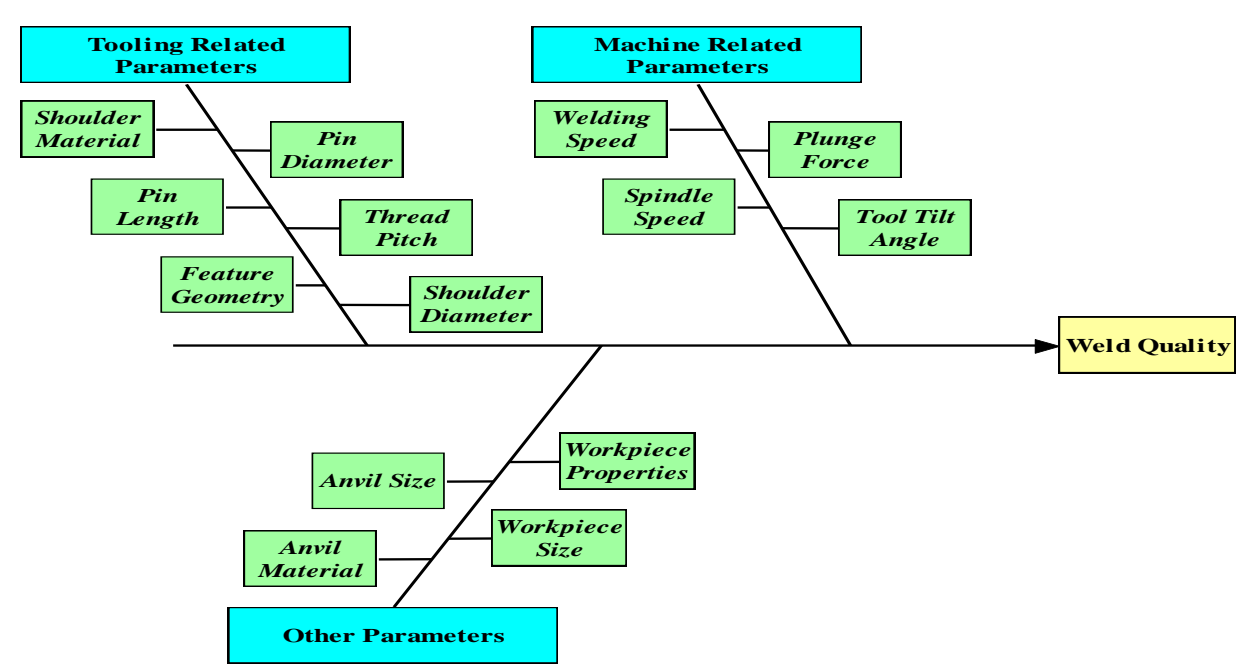

Fig. 3. Cause and effect diagram for friction stir welding process

\section{Experimental setup}

The experimental setup for the friction stir welding process consists of four major subsystems: (a) tool and tool-holding system (b) workpiece holding system (c) motion supply system (d) machine frame. FSW involves frictional heating, rotational and translational movement of tool, plunge force, etc. and hence, strength, heat resistance capability, good machinability, easy availability and low cost should be taken into consideration during selection of material for fabricating the machine setup. Tool and tool holding system consists of rotating FSW tool and a quill to hold the tool. This rotating tool is the most crucial element of FSW technique. It consists of pin and shoulder. In FSW, when rotating tool travels along the surfaces to be joined by the process, it serves primarily three objectives: heating of workpiece by friction between tool pin and solder with workpiece and resulting severe plastic deformation of workpiece material; stirring of material by simultaneous rotational and translational motion of tool to cause coalescence and to filling up the holes; and suppression of the heated metal underneath the shoulder to restrict the metal flow upto a level of frontal face of solder (Mishra and Mahoney, 2008). The common designs for pin are cylindrical with or without threads (Costa et al., 2015, Dubourg et al., 2010; Elangovan et al., 2008) conical with or without threads (Guo et al., 2013; Upadhyay and Reynolds, 2014; Ghetiya and Patel, 2015) four flute square, four flute cylindrical (Bahrami et al., 
2014 ) etc. The tool shoulder can be a either cylindrical, with negative or positive scroll (Krasnowski et al., 2015)or it can be concave or convex (Rajakumar et al., 2011; Bahrami et al., 2014). The selection of FSW tool is a critical issue as its profile influences the stirring of material and quality of the weld to be done. The key factors in deciding FSW tool are hardness of workpiece material and amount of material to be stirred. Different FSW tool pin and shoulder geometry are illustrated in Fig. 4.

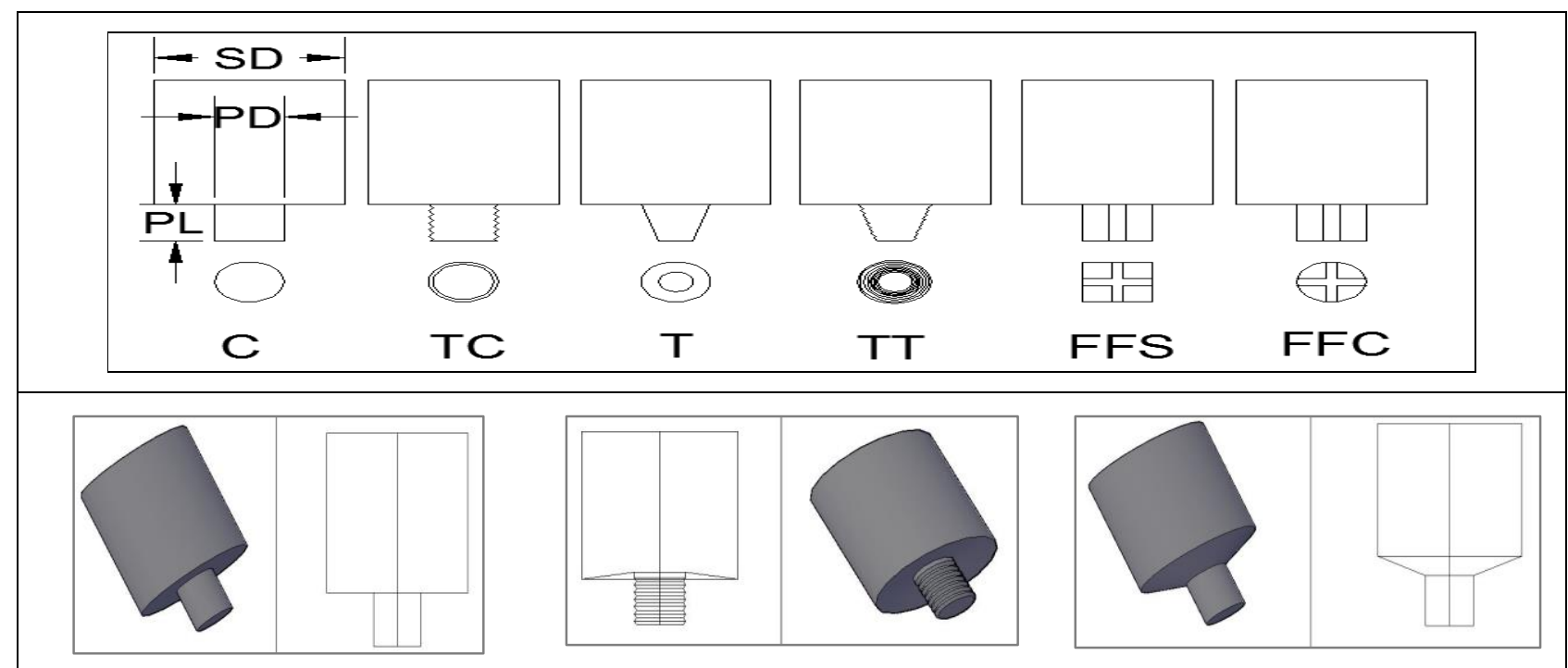

(a)

Flat end face shoulder

Concave shoulder

Convex shoulder

(1)

(b)

Concentric circles shape shoulder

Scroll shape shoulder

Fig. 4. (a) FSW tool with different pin geometry (C: Cylindrical; TC: Threaded cylindrical; T: Tapered; TT: Threaded taper; FFS: Four flute square; FFC: Four flute cylindrical)(b) FSW tools with different shoulder geometry

The workpiece holding system contains a specially designed and shaped fixture to hold the workpieces properly. Fixture consists of base plate and clamps and it helps to keep the faying surface in contact during the process. Motion supply system consists of motors to provide rotational motion to the FWS tool and translational motion to the workpiece. Machine frame consists of bed for holding the fixture, spindle head to hold the quill, a vertical column and knee elevating screw for positioning of bed and to provide necessary support to the machine setup. 


\section{Literature review}

In present day scenario the application of high strength, low weight metal alloys are increasing very rapidly in the arena of aerospace, aircraft, marine, etc. Producing sound joints in these materials employing existing welding techniques is major concern. FSW process owing to its unique characteristics is emerging as an alternative welding technique.According to available literatures FSW technique is capable of joining simmilar or dissimilar metals or alloys and the list of workpiece materials can be joined by FSW technique includes aluminium, magnesium, copper, steel, zinc, nickel and its alloys. A comparative study of published research work on FSW of different materials is illustrated in Fig. 5. It is obvious from Fig. 5 that most of the research work is concentrated on aluminium owing to its industrial applications and difficulties experienced by researchers during fusion welding of aluminium.In this chapter an attempt has been made to summarize the work already carried out and to provide a guideline for future research work. A brief overview of different aspects of FSW process is presented here.

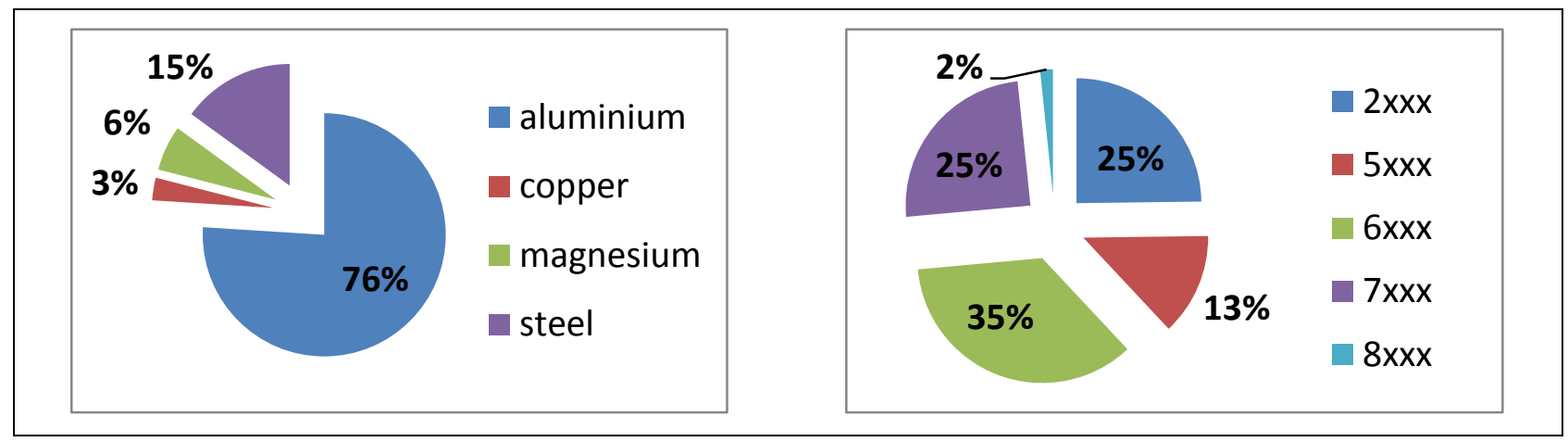

Fig. 5.Comparative study of published research work on FSW

\subsection{FSW of aluminium and its alloys}

Aluminium and its alloys are widely used in aerospace, marine and automobile applications owing to their unique characteristics: high strength to weight ratio, high corrosion resistance, high ductility, etc. But joining of aluminium and its alloys by fusion technique is troublesome which establishes the necessity of FSW technique for joining of aluminium and its alloys. Rhodes et al. (1997) probably the first one who picked up research on FSW for aerospace materials. After that it is accelerated by Liu et al. (1997) as they carried out FSW to join 6061-T6 aluminium alloy under different conditions of rotational and welding speeds. It is evident from experiments that the hardness in stir zone near to crest is $55 \mathrm{VHN}$ and near to trough is $65 \mathrm{VHN}$. The grain size is also altered in nugget zone. Colligan (1999) studied plastic deformation behaviour in nugget zone during FSW and reported that the movement of material in nugget zone partially influenced by the tool pin. In 1999 Sato et al. examined the microstructure of friction stir welded aluminium 6063. Formation of three types of microstructure regions: fine recrystallized grains; coarse equiaxed grains and recovered grains is observed. Hardness is found reduced in nugget zone owing to low density and dissolution of precipitates. Jata et al. (2000) scrutinized microstructural behaviour of 
nugget zone and tried to correlate it with strain rate and temperature of nugget zone. They stated that grain size in weld zone varies with strain rate and temperature. In addition, Jata et al. (2000) examined the effects of post weld condition (temperature of $121^{\circ} \mathrm{C}$ for 24 hours) on microstructure and mechanical properties of FSW aluminium joint. It is observed that without post weld condition tensile strength and elongation decrease and fracture occurs at HAZ while in case of post weld condition tensile strength and ductility remain constant; however fatigue crack growth resistance increases in HAZ and decreases in nugget zone. Charit et al. (2002) and Su et al. (2003) carried out experimental investigation on aluminium 7xxx alloys and explained the microstructural and tensile properties of FSW joints. Charitet al. (2002) further reported that grain possesses superplastic behaviour in HAZ results in enhanced strength. Lim et al. (2004) and Cavaliere et al. (2006, 2008) applied FSW on aluminium $6 \mathrm{xxx}$ alloy to evaluate the effect of rotational and translational speeds on tensile behaviour of weld and reported that ductility of weld is adversely affected by tool rotation. In 2006, Schmidt applied this technique for butt joining of aluminium alloy 2024-T3 and inserted thin copper strip as a marker material; estimated average velocity of flow materials through shear layer. Cavaliere and Cerri (2005) employed FSW technique to join two dissimilar aluminium alloys 2024-7075 and obtained weld free of porosity defects. It is observed that in nugget zone grains are fully recrystallized and microhardness increases as the distance increases from centre line up to $2 \mathrm{~mm}$ for both sides. Fine and more equiaxed grain structure are observed on 2024 side as compared to 7075 side. It is concluded that all the specimen fracture from HAZ near 2024 side and possess high ductility as compared to parent metal. Chen et al. (2006) studied the effect of base metal conditions on mechanical and metallurgical properties of friction stir welded 2219 aluminium alloys in two conditions: $2219-\mathrm{O}$ and 2219-T6. It is found that tensile strength efficiency is superior in case of 2219-O as compared to 2219-T6 alloys. Moreover, it is evident that microstructure of 2219-O is not having visible interface between nugget zone and TMAZ. Tilt angle of FSW tool also plays a crucial role to control weld defects. Chen et al. (2006) observed that low tilt angle reduces the flow of materials during the process that results in formation of kissing bond like structure in stir zone while high tilt angle results in flashes. Tensile strength decreases owing to formation of kissing bond structure.FSW tool is one of the most vital elements of FSW setup as pin profile and shoulder profile regulate the amount of material stirred. Scialpi et al. (2007), Elangovan et al. (2008) and Salari et al. (2014) described the effect of pin and shoulder geometry on process performance of FSW. During FSW of 6082 aluminium Scialpi et al. (2007) reported that shoulder profiles influence grain size in nugget zone and thus mechanical properties of joints. The grain size in stir zone is observed very fine and equiaxed as compared to parent metal. Elangovan et al. (2008) described the effect of tool geometries on FSW of 6061 aluminium alloy. It is evident that square pin produces welds free of metallurgical defects and with high tensile strength. Later Salari et al. (2014) investigated the effect of pin profile during friction stir lap welding. It is observed that pin profile is having significant influence on process performance. They further reported that step conical threaded pin produces highly strength joint. Beside this, Rodrigues et al. (2009) investigated mechanical and metallurgical aspects of FSW joints using two types of tool: conical shoulder and scroll 
shoulder. It is observed that application of conical shoulder results in few bigger coarsened precipitates in stir zone as compared to scroll shoulder and therefore, elongation is reduced $30 \%$ in conical shoulder and $70 \%$ in scroll shoulder. Furthermore In 2012, Palanivel et al. carried out FSW for joining of two dissimilar aluminium alloys (5083-6351) employing four different pin profiles at three different levels of rotational speed. They reported that pin profile influences the mixing and flow of material during the process that result in changed properties. In addition, it is concluded that taper pin profile produces defect in weld. The generation of frictional heat and temperature distribution during FSW process is another aspect to be examined as it influences the microstructure and mechanical properties of FSW joints (Hwang et al., 2008; Xu et al., 2009; Lorrain et al., 2010; Al-Jarrah et al., 2014). Hwang et al. (2008) practically explored the temperature distribution and its effect on properties of friction stir welded 6061 aluminium alloy. It is found that hardness is same on both the side (advance side and retreating side) but temperature on advancing side is slightly higher than retreating side. In TMAZ and HAZ, tensile strength and hardness both are observed 50\% lower than base metal. On the other hand $\mathrm{Xu}$ et al. (2009) performed experiments on aluminium alloy plates of 2219-O using thermocouples to determine the distribution of temperature during FSW. It is evident that stir zone is fully recrystallized and at the top of weld grain size is slightly coarser as compared to bottom. Xu et al. (2009) further reported that tensile strength of FSW joint increases with increasing rotational speed; however, elongation is adversely effected. It is observed that fractured is ductile in nature and hardness is enhanced from bottom to top. Lorrain et al. (2010) investigated the effect of cooling on microstructure and mechanical properties of joint of aluminium 7075 alloy plates. It is observed that nugget zone is free of defects and strength and hardness is found enhanced in TMAZ. Lu et al. (2011), Heidarzadeh et al. (2012) and Liu et al. (2012)carried out experimental investigation to study the effect of process parameters on process performance characteristics during FSW of 2219-O, 6061 and 2219 alloy respectively. It is reported that tensile strength improves with increase in welding speed while feed rate affects it adversely. Beside this, Costa et al. (2012) investigated the fatigue behaviour of friction stir welded 6082 aluminium alloys and reported that the tunnel and other serious defects affect the fatigue strength. Later, Guo et al. (2014) described the effect of process parameters on mechanical properties of FSW joint of two dissimilar aluminium alloys (6061-7075). It is found that the mixing is more effective when 6061 alloy is placed on the advancing side. The grain size is found decreasing with increase in feed rate. In addition, it is evident that the fracture occurs on 6061 side that has minimum hardness, superior tensile strength and good ductility. Fahimpour et al. (2012) compared FSW joint with GTAW joint of aluminium alloys of 6061 and concluded that FSW joint is having higher corrosion resistance property. Although, in both the cases the corrosion resistance of joint is less than that of base metal because of grain size in nugget zone. On the other hand, Xu et al. (2012) carried out a comparative study of FSW and fusion welding and reported that the fatigue strength of friction stir lap welded joint is found inferior than fusion welded lap joint owing to presence of hooking defect. In most recent work, Upadhyay and Reynolds (2014) and Krasnowski et al. (2015) studied the effect of backing plates and weld configuration respectively on metallurgical and mechanical properties of FSW 
joints. Upadhyay and Reynolds reported that application of composite base plate in place of steel base plate improves tensile strength and microhardness while Krasnowski et al. concluded that the two sided weld exhibits lower strength than single sided weld.

\subsection{FSW of steel}

Fusion welding affects the microstructure of steel and owing to this steel losses their corrosion resistance and toughness properties. To the best knowledge of authors Thomas et al.(1999) is probably the first one to check out the feasibility of FSW of steel. They carried out FSW technique on 12\% chromium alloy and low carbon steel in a modified vertical milling machine to test the bending and tensile strength of joint. Thereafter Lienert et al. (2003) experimentally analyzed the possibility of FSW of mild steel and reported the effect of process parameters on metallurgical and mechanical properties of FSW joint. Thermocouples are also used to determine the temperature distribution during the process. However, very high tool wear is observed at initial stage for plunging action of tool. Reynolds et al. (2003) attempted FSW for 304L and experiments are carried out at constant feed rate and two different rotational speeds. It is evident that grain size of joint is less than that of base metal and existence of narrow band grain in stir zone for both rotational speeds. It is obvious that a joint with superior ductility than fusion welding is obtained. In 2005 Sato et al. investigated the properties of friction stir welded 2507 super duplex stainless steel using CBN tool of $25 \mathrm{~mm}$ diameter and at 3.5 degree tilt angle. It is observed that in SZ the microstructure of joint contains refined grains of ferrite and austenite and hence hardness and strength is increased. It is further evident that the fracture occurs between HAZ and TMAZ line on retreating side. It is witnessed that percentage of carbon content affects mechanical and metallurgical properties of friction stir welded low carbon steel joints (Ueji et al., 2006). It is found that with increase in carbon content the tensile strength increases rapidly with minor change in welding speed upto a certain limit and then starts decreasing. With increase in carbon content portion of austenite is found increasing in obtained ferrite-austenite structure. Moreover, in case of S12C steel austenite is observed transformed into pearlite but the distribution is not uniform. Sato et al. (2007) investigated the metallurgical properties of frictions stir welded ultrahigh carbon steel and examined martensitic structure in stir zone and mixed in the HAZ. Later in 2008, Saeid et al. described the effect of welding speed on characteristics of friction stir welded duplex stainless and stated that microstructure of stir zone consists of equiaxed grains of $\alpha$ and $\gamma$ phases. They further reported that the size of grains decreases with increasing welding speed and the hardness and tensile strength enhances with increase in feed rate. Cho et al. (2012) and Han et al. (2014) investigated the microstructure of friction stir welded stainless steel plates. Cho et al. observed that the hardness of nugget zone is higher because of presence of bainitic structure in nugget zone. On the other hand Han et al. witnessed formation of fine grains in nugget zone and TMAZ owing to mechanical stirring and heating. It results in joint with superior impact strength. In recent work, Zhou et al. (2015) checked out the possibility to fill up the keyhole at the end of the process during FSW of 316L stainless steel using consumable tool of 316L steel bar. Fine grain microstructure is obtained in nugget zone. Although void defects are observed at the bottom surface of keyhole. Beside this, Sun and Fujii (2015) utilized 
cathodic hydrogen charging method for evaluation of hydrogen embrittlement during FSW of stainless steel. It is observed that due to cathodic hydrogen charging no phase transformation occurs during the process. The fine grain size is obtained in stir zone. However, hydrogen blisters are blocked in stir zone results in formation of small cracks.

\subsection{FSW of copper and its alloys}

Copper has high thermal and electrical conductivity, excellent corrosion resistance, good strength and ductility that make it useful in many industrial applications. Owing to its high thermal diffusivity and oxidation rate welding of copper by fusion welding technique is found difficult. FSW is emerging as substitute for fusion welding to perform joining of copper. Lee and Jung(2004) probably the first researcher carried out research on FSW of copper. The experiment is conducted on $4 \mathrm{~mm}$ thick copper plates with the help of steel tool. It is observed that the size of grain in the nugget zone is very fine and equiaxed as compared to base metal. It is obvious from the study that the strength obtained by FSW is higher than that of electron beam welding. Khodaverdizadeh et al. (2012) analysed the work hardening behaviour of FSW joints of pure copper alloys. The experiments are conducted at two different rotational speeds and constant feed rate and vice versa and it is evident that both factors influence the mechanical and metallurgical properties of copper joint. The grain size in SZ and HAZ decreases with increasing rotational speed and decreases in welding speed. Owing to this hardening capacity increases and stain hardening exponent decreases. Lin et al. (2014) compared the properties of friction stir welded pure copper plates with TIG and it is observed that FSW of copper produced $13 \%$ more efficient weld than TIG.

\subsection{FSW of other materials}

Beside aluminium, copper and steel FSW has also been attempted for magnesium, brass, titanium, plastics, etc.; a brief discussion of findings is presented here. Lee et al. (2005) employed FSW for joining of high strength titanium alloy plates. The experiment is conducted at constant welding and rotational speed. The microstructure of the titanium is found different from friction stir welded aluminium alloys. It is observed the presence of deformational twins with variation in density in nugget zone. It is evident that twins are denser at the top owing to direct contact between workpiece and tool and it decreases towards bottom. Phase transformation is also observed in transition zone. Tensile strength in the nugget zone is witnessed slightly lower than the base metal and fracture occurred at HAZ. Later, Zhang et al. (2008) carried out experimental investigation of friction stir butt welding of titanium alloy plates and scrutinized the microstructure of joint. Fine $(\alpha+\beta)$ lamellar structure is observed in nugget zone whereas bimodal type structure is observed in HAZ. The hardness and tensile strength of SZ is found superior than base metal however, it is inferior in case of HAZ and hence, tensile specimens are found fractured in HAZ. Meran (2006) reported experimental findings of FSW for brass and compared the joint with fusion welded joint. No evaporation of zinc and copper is found occurred during FSW. The mechanical properties of the joint are obtained similar to the base metal. In addition, 
less number of pores is observed in microstructure in nugget zone as compared to fusion welded brass. Xunhong and Kuaishe (2006) investigated the properties of friction stir welded magnesium Z31 alloy at various rotational and transverse speeds with FSW tool having $4 \mathrm{~mm}$ pin and $12 \mathrm{~mm}$ shoulder diameter. Fine grains with intermetallic compound are observed in nugget zone. The microhardness of nugget zone is found superior than base metal and fracture occurred in HAZ. However, the tensile strength is obtained slightly lesser than base metal. Cao and Jahazi (2011) reported the effect of rotational speed and pin length on friction stir lap welded joint of magnesium Z31. It is observed that tensile shear load increases with increasing heat input upto a limit and then starts decreasing while shear strength is found increasing with increase in plunging depth of pin. Forcellese et al. (2012) also studied mechanical and metallurgical behaviour of friction stir welded Z31 magnesium alloy and the findings coincide with previous results. Payganeh et al. (2011) carried out friction stir welding of polypropylene composite plates and studied the effect of tool geometry, tool tilt angle, and rotational speed on joint strength. They also reported the existence of an optimum rotational speed for maximum tensile strength of weld. After that Panneerselvam and Lenin (2014) tried FSW technique to join two nylon sheets with mild steel tool. They investigated the effect of tool direction on FSW process and concluded that left hand threaded pin profile with anticlockwise and right handed thread profile with clockwise direction produce superior quality weld. In reverse case small blowholes and large cavity can be observed. Schneider et al. (2015) employed FSW for joining of nickel based alloy and reported that the joint produced by FSW is defect free as compared to fusion welded joints. It is also observed that the grains size produced by FSW is reduced up to $85 \%$ than the fusion process. However, tensile strength is evident slightly lower than the parent metal.

\subsection{FSW of dissimilar metals}

Every metal has its unique characteristics and owing to this use of dissimilar metals increases rapidly in many industrial applications. However, welding of dissimilar metal by fusion process is troublesome owing to occurrence of defects: porosity, improper melting and mixing and poor strength, etc. It is reported in literature that FSW joint of dissimilar metal possesses equal strength as that of base metal with minor defects as compared to fusion welding techniques. Takehiko et al.(2006) examined joint properties of two dissimilar metal alloys (aluminium and steel) and observed that the maximum strength is obtained at tool pin offset not more than 0.2 $\mathrm{mm}$ toward the steel side. It is also reported that strength of the joint relies on rotational speed that should be optimum. Liu et al. (2008) analysed the properties of FSW joint during joining of copper with aluminium alloy. No intermetallic compounds are observed in the stir zone. It is found that the mixing of copper and aluminium toward the copper side is lamellar structure and mixed structure on the aluminium side. During the tensile testing, specimen is fractured toward the copper side and the tensile strength is observed identical of copper and 6\% less than that of aluminium. Chen and Nakata (2009) also attempted FSW joining of aluminium with titanium and outcomes are found in accordance with previous findings. 


\subsection{Nanoparticle inclusions, quenching and preheating}

In present scenario monolithic alloys are readily replacing by aluminium matrix composites (AMCs) in many engineering industries like aerospace, automotive and marine owing to their superior properties. Reinforcement of hard ceramic particles into the molten aluminium has led to development of AMCs. It is observed that with increase in amount of ceramic particles hardness, impact strength, and density of AMCs enhance while bending strength increases up to certain percentage and then starts decreasing. It is obvious from available literature that mechanical properties of FSW joints enhance with increase in reinforcement fraction and adversely affect the ductility. Dinaharan and Murugun (2012) experimentally investigated the effect of inclusion of $\mathrm{ZrB}_{2}$ particles on tensile strength of FSW joints and it is observed that owing to unique features of $\mathrm{ZrB}_{2}$ : strong covalent bond, high melting point, high strength and hardness, good thermal conductivity and thermal shock resistance tensile strength of FSW joints increases significantly with increase in percentage amount of $\mathrm{ZrB}_{2}$. Bahrami et al. (2014) investigated the effect of inclusion of $\mathrm{SiC}$ on strength of FSW joints and reported that these included particles are found to act as barriers against recrystallization during the process. It is evident that owing to particle inclusion strength of FSW joint improves upto such an extent that during tensile test specimen is found fractured from base metal. However, FSW tool experiences higher wear rate for the presence of SiC. Kumar and Murugan (2014) observed enhancement in mechanical and thermal properties of AMCs owing to presence of AlNp. Similar phenomenon is observed by Misak et al. (2014) during FSW of aluminium alloy with CNT particles inclusion.

The quality of joints produced by FSW depends upto a large extent on flow of materials in the stir zone and therefore a number of attempts have been tried by researchers to increase the flow of material in stir zone by varying pin or solder geometry. Preheating of workpiece before FSW can be established as an alternative. Preheating softens the materials and increases the flow of materials in the stir zone and thus reduces the welding forces and enhances efficiency (Sinclair et al. 2010). It is observed that in FSW with preheating strength of joints increases $8 \%$ as compared to conventional FSW. Preheating enhances the material flow and marginal modification in deformation behaviour resulting in increasing hardness of nugget zone (Yaduwanshi et al., 2014). Owing to additional heat HAZ increases and TMAZ decreases. Thermal stresses also increase owing to presence of additional heat in HAZ (Yaduwanshi et al., 2013). In case of FSW of dissimilar metals preheating increases material flow in SZ and decreases void formation. Yaduwanshi et al. (2014) investigated the effect of preheating during FSW of dissimilar metals and it is found that the developed joints are free from void defects. In addition, FSW joints are obtained with enhanced tensile and bending strength. Furthermore, additional heat reduces friction between tool and workpiece; results in low tool wear and longer tool life (Zargar and Kukatpally, 2013)

Rapid cooling using different quenching mediums namely brine solution, water, oil, etc. increases yield strength and minimizes residual stresses. Furthermore, slow quenching enhances resistance to stress corrosion cracking. The same concept can be 
applied to improve strength of FSW joints. According to the best knowledge of authors available literature lacks experimental investigation of quenching of FSW joints and hence, it can be an aspect to be explored significantly.

\section{Conclusions and future scope}

In this chapter, a critical review of different aspects of FSW technique has been illustrated. It has been decided to present the major findings related to FSW at one place so as to provide a clear picture to the reader. Following points can be concluded:

- Friction stir welding owing to its unique characteristics: low distortion and shrinkage even in long welds, free of arc, filler metal, and shielding gas, low HAZ, free of spatter and porosity defect is emerging as an alternative to fusion welding. FSW is found suitable for joining similar or dissimilar metals or alloys including aluminium, magnesium, copper, steel, zinc, nickel and its alloys, plastics, etc.

- Like traditional fusion welding butt and lap joint can be carried out in friction stir welding. Although, no special preparation is needed. Moreover, it is observed that FSW shows significant enhancement in tensile strength, ductility, fatigue, and facture toughness as compared to fusion welding.

- It is evident that FSW process parameters: tool rotation rate, traverse speed, spindle tilt angle influence the mechanical and metallurgical behaviour of joints and hence, are crucial to produce sound and defect-free weld.

- It is obvious that FSW tool regulates the amount of material stirred and frictional heat and hence, geometry of pin and shoulder are deciding factor to obtain sound welds. Despite of considerable attention on FSW technique, following issues have not received enough attention and need to be addressed:

- According to available literature, most of the research work is focused on friction stir welding of aluminium, copper and magnesium. Friction stir welding of alloys, plastics, composite materials, etc. is having huge scope for future research.

- The influences of the input process parameters on process performance characteristics and interaction effects are not significantly explored. In-detail study of contribution of the individual input process parameters on process performance characteristics is lacking in literature.

- Mechanism of materials flow, tool geometry design, wearing out of welding tool, force distribution during welding needs proper attention.

- The tribological, corrosional and surface topographical behaviour of friction stir welded joints are not elaborately discussed in literature.

- In-detail study is required to explore the effect of preheating, nanoparticle inclusion and quenching on mechanical and metallurgical behaviour of FSW joints.

- No proper guideline in terms of mathematical/theoretical model of process performance parameters of FSW is available for selecting input parameters to obtain desired output. 


\section{References}

Al-jarrah, J. A.; Swalha, S.; Mansour, T. A.; Ibrahim, M.; Al-Rashdan, M.\& Al-Qahsi, D. A. (2014).Welding equality and mechanical properties of aluminum alloys joints prepared by friction stir welding. Materials \& Design, 56,929-936

Backer, J. D. \& Bolmsjö, G. (2014).Temperature control of robotic friction stir welding using the thermoelectric effect. Int. J. of Adv. Manuf. Technol., 70, 375-383.

Bahrami, K.; Givi, M. K. B.; Dehghani, K. \& Parvin, N. (2014). On the role of pin geometry in microstructure and mechanical properties of AA7075/SiC nano-composite fabricated by friction stir welding technique. Materials and Design, 53, 519-527

Cao, X. \& Jahazi, M. (2011). Effect of tool rotational speed and probe length on lap joint quality of a friction stir welded magnesium alloy. Materials and Design, 32, 1-11 Cavaliere, P. \& Cerri, E. (2005).Mechanical response of 2024-7075 aluminium. J. of Material Science, 3669-3676

Cavaliere, P.; Nobile, R.; Panella, F. W. \& Squillace, A. (2006). Mechanical and microstructural behaviour of 2024-7075 aluminium alloy sheets joined by friction stir welding. Int. J. of Machine Tools and Manufacture, 46, 588-594

Cavaliere, P.; Squillace, A. \& Panella., F. (2008).Effect of welding parameters on mechanical and microstructural properties of AA6082 joints produced by friction stir welding. J. of Materials Processing Technology, 200, 364-372

Charit, I.; Mishra, R. S. \& Mahoney, M. W. (2002). Multi-sheet structures in 7475 aluminum by friction stir welding in concert with post-weld superplastic forming. Scripta Materialia, 47, 9, 631-636

Chen, H. B.; Keng Y.; Tao L.; Chen, S. B.; Cheng, Y. J.\& Yong, Z. (2006). The investigation of typical welding defects for 5456 aluminum alloy friction stir welds. Material science and engineering, 433, 64-69

Chen, Y.; Liu, H. \& Feng, J. (2006). Friction stir welding characteristics of different heat-treated-state 2219 aluminum alloy plates. Material Science and Engineering, 420, 21-25

Chen, Y. C. \& Nakata, K. (2009). Microstructural characterization and mechanical properties in friction stir welding of aluminum and titanium dissimilar alloys. Material and Design, 30, 469-474

Cho, H. H.; Kang, S. H.; Kim, S.H.; Oh, K. H.; Kim, H. J.; Chang, W. S. \& Han, H.N. (2012). Microstructural evolution in friction stir welding of high-strength line pipe steel. Materials \& Design, 34, 258-267

Colligan, K. (1999). Material flow behaviour during friction stir welding of aluminum. Supplement to the Welding Journal, 229-237

Costa, J.D.; Ferreira, J. A. M., Borrego, L. P. \& Abreu, L. P. (2012). Fatigue Behaviour of AA6082 Friction Stir Welds under Variable Loadings. International Journal of Fatigue, 37, 8-16

Costa, M. I.; Verdera, D.; Costa, J. D.; Leitao, C. \& Rodriguesa, D. M. (2015). Influence of pin geometry and process parameters on friction stir lap welding of AA5754-H22 thin sheets. J. of Materials Processing Technology, 225, 385-392. 
Dawes C. \& Thomas W. (1995).TWI Bulletin, 6,124

Dinaharan, I. \& Murugan, N. (2012). Optimization of friction stir welding process to maximize tensile strength of AA6061 / $\mathrm{ZrB}_{2}$ in-situ composite butt joints.Met.Mater.Int, 18,1, 135-142

Dubourg, L.; Merati, A. \& Jahazi, M. (2010). Process optimisation and mechanical properties of friction stir lap welds of 7075-T6 stringers on 2024-T3 skin. Materials and Design, 31, 3324-3330

Elangovan, K.; Balasubramanian, V. \& Valliappan, M. (2008). Influences of tool pin profile and axial force on the formation of friction stir processing zone in AA6061 aluminium alloy. Int. J. Adv. Manuf. Technol, 38, 285-295

Fahimpour, V.; Sadrnezhaad, S. K. \& Karimzadeh, F. (2012).Corrosion behavior of aluminum 6061 alloy joined by friction stir welding and gas tungsten arc welding methods. Materials \& Design, 39, 329-33

Forcellese, A.; Gabrielli, F. \& Simoncini, M. (2012). Mechanical properties and microstructure of joints in az31 thin sheets obtained by friction stir welding using pin and pinless tool configurations. Materials and Design, 34, 219-229

Ghetiya, N. D. \& Patel, K. M. (2015).Prediction of tensile strength and microstructure characterization of immersed friction stir welding of aluminium alloy aa2014-T4. Indian J. of Material and Sciences, 22,133-140

Guo, J. F.; Chen, H. C.; Sun, C. N.; Bi, G.; Sun, Z. \& Wei, J. (2013). Friction stir welding of dissimilar materials between AA6061 and AA7075 al alloys effects of process parameters. Material and Design, 56, 185-192

Han; Jian; Li, H.; Zhu, Z.; Barbaro, F.; Jiang, L.; Xu, H. \& Ma, L. (2014). Microstructure and mechanical properties of friction stir welded $18 \mathrm{cr}-2 \mathrm{mo}$ ferritic stainless steel thick plate. Materials \& Design, 63, 238-246

Heidarzadeh, A., Khodaverdizadeh, H., Mahmoudi, A., \& Nazari, E. (2012). Tensile Behavior of Friction Stir Welded AA 6061-T4 Aluminum Alloy Joints. Materials \& Design, 37, 166-173

Hwang, Y. M.; Kang, Z. W.; Chiou, Y. C. \& Hsu, H. H. (2008). Experimental study on temperature distributions within the workpiece during friction stir welding of aluminum alloys. Int. J. of Machine Tool and Manufacturing, 48, 778-787

Jata, K. V.; Sankaran, K. K. \& Ruschau, J. J. (2000). Friction-stir welding effects on microstructure and fatigue of aluminum alloy 7050-T7451. Metallurgical and Materials Transactions, 2181-2192

Khodaverdizadeh, H.; Mahmoudi, A.; Heidarzadeh, A. \& Nazari, E. (2012). Effect of friction stir welding ( FSW ) parameters on strain hardening behaviour of pure copper joints. Materials and Design, 35,330-334

Krasnowski, K.; Hamilton, C. \& Dymek, S. (2015).Influence of the tool shape and weld configuration on microstructure and mechanical properties of the Al 6082 alloy fsw joints. Archives of Civil and Mechanical Engineering, 5, 133-141

Kumar, B. A. \& Murugan, N. (2014). Optimization of friction stir welding process parameters to maximize tensile strength of stir cast AA6061-T6/AlN $N_{P}$ composite. Materials \& design, 57, 383-93 
Lee, W. \& Jung, S. B. (2004). The joint properties of copper by friction stir welding. Materials Letters, 58, 1041-1046

Lee, W.; Lee, C. Y.; Chang, W. S.; Yeon, Y. M. \& Jung, S. B. (2005). Microstructural investigation of friction stir welded pure titanium. Materials Letters, 59, 3315-3318

Lienert, T. J.; Stellwag, W. L.; Grimmett, B. B. \& Warke, R. W. (2003). Friction stir welding studies on mild steel. Welding Journal, 1s-9s

Lim, S.; Kim, S.; Lee, C. \& Kim, S. (2004). Tensile behavior of friction-stir-welded A356-T6 / Al 6061-T651 Bi-alloy plate. Metallurgical and Materials Transactions, 2837-2843

Lin; W. J.; Chang, H. C. \& Wu, M. H. (2014). Comparison of mechanical properties of pure copper welded using friction stir welding and tungsten inert gas welding. J. of Manufacturing Processes, 16, 296-304

Liu, G.; Murr, L. E.; Niou, C. S.; McClure, J. C. \& Vega, F. R. (1997). Microstructural aspects of the friction-stir welding of 6061-T6 aluminum. Scripta Materialia, 37, 3, 355-361

Liu, H.; Zhang, H.; Pan, Q. \& Yu, Y. (2012).Effect of friction stir welding parameters on microstructural characteristics and mechanical properties of 2219-T6 aluminum alloy joints. Int. J. Mater Form, 235-241

Liu, P.; Shi, Q.; Wang, W.; Wang, X. \& Zhang, Z. (2008). Microstructure and XRD analysis of fsw joints for copper t2/aluminium $5 \mathrm{a} 06$ dissimilar materials. Materials Letters, 62, 4106-4108

Lohwasser, D. \& Chen, Z. (2010). Friction stir welding: from basics to applications, Woodhead Publishing limited, New Delhi

Lorrain; Olivier; Favier, V.; Zahrouni, H. \& Lawrjaniec, D. (2010). Understanding the material flow path of friction stir welding process using unthreaded tools. $J$. of Materials Processing Technology, 210, 603-609

Lu, H.; Peilin, L.; Zhongfeng, X. \& Meng X. (2011). The influence of thread form on refilling friction stir welding of 2219 aluminum alloy sheets. J.Transactions of JWRI,41-42

McNelley, T. R.; Swaminathan, S. \& Su, J. Q. (2008). Recrystallization mechanisms during friction stir welding/processingof aluminum alloys. Scripta Materialia, 58, 349354

Mahoney, M. W.; Rohdes, C. G.; Flintoff, J. G.; Surling,R. A. \& Bingel, W. H. (1998). Properties of friction-stir-welded 7075 T651 aluminum. Metallurgical and Materials Transactions, 29,1955-1964

Meran, C. (2006). The Joint Properties of Brass Plates by Friction Stir Welding. Materials \& Design, 27, 719-726

Messler Jr R. W. (2004). Principles of welding - processes, physics, chemistry, and metallurgy. Wiley-VCH

Misak, H. E.; Widener, C. A. \& Burford, D. A. (2014). Fabrication and characterization of carbon nanotube nanocomposites into 2024-T3 al substrates via friction stir welding process. J. of Engineering Materials and Technology, 136, 3-7. 
Mishra, R. S. \& Mahoney, M. W. (2008). Friction stir welding and processing, ASM International, Ohio

Palanivel, R., Mathews, P. K.; Murugan, N. \& Dinaharan, I. (2012). Effect of tool rotational speed and pin profile on microstructure and tensile strength of dissimilar friction stir welded AA5083-H111 and AA6351-T6 aluminum alloys. Materials \& Design, 40

Panneerselvam, K. \& Lenin, K. (2014). Joining of nylon 6 plate by friction stir welding process using threaded pin profile. Materials \& Design, 53, 302-307

Payganeh, G. H.; Mostafa Arab, N. B.; DadgarAsl, Y.; Ghasemi, F. A. \& Saeidi, M. (2011). Effects of friction stir welding process parameters on appearance and strength of polypropylene composite welds. Int. J. of Physics Sciences, 6, 4595-4600

Rajakumar, S.; Muralidharan, C. \& Balasubramanian, V. (2011). Influence of friction stir welding process and tool parameters on strength properties of AA7075-T6 aluminium alloy joints. Materials and Design, 32, 535-549

Reynolds, A. P.; Tang, W.; Gnaupel-Herold, T. \& Prask, H. (2003). Structure, properties, and residual stress of 304L stainless steel friction stir welds. Scripta Materialia, 48, 1289-1294

Rhodes, C. G.; Mahoney, M. W.; Bingel, W. H.; Spurling, R. A. \& Bampton, C. (1997). Effects of friction stir welding on microstructure of 7075 aluminum. Scripta Materialia, 36, 1, 69-75

Rodrigues, D. M.; Loureiro, A.; Leitao, C.; Leal, R. M.; Chaparro, B. M. \&Vilaça, P. (2009). Influence of friction stir welding parameters on the microstructural and mechanical properties of AA 6016-T4 thin welds. Materials \& Design, 30

Saeid, T; Abdollah-zadeh, A.; Assadi, H. \& MalekGhaini, F. (2008). Effect of friction stir welding speed on the microstructure and mechanical properties of a duplex stainless steel. Materials Science and Engineering, 496, 262-268

Salari, E.; Jahazi, M.; Khodabandeh, A. \& Nanesa, H. G. (2014). Influence of tool geometry and rotational speed on mechanical properties and defect formation in friction stir lap welded 5456 aluminum alloy sheets. Materials \& Design, 58, 381-389 Sato, Y. S.; Yamanoi, H.; Kokawa, H. \& Furuhara, T. (2007). Microstructural evolution of ultrahigh carbon steel during friction stir welding. Scripta Materialia, 57, 557-560

Schmidt, H. N. B.; Dickerson, T. L. \& Hattel, J. H. (2006). Material flow in butt friction stir welds in AA2024-T3. Acta Materialia, 54, 1199-1209

Schneider, J. A.; Williston, T. L.; Murphy, C.; Varner, J. \&Walker, H. B. (2015). Solid state joining of nickel based alloy, Haynes 230. J. of Materials Processing Technology Transactions, 1-55

Scialpi, A.; Filippis, L. A. C. D. \& Cavaliere, P. (2007). Influence of shoulder geometry on microstructure and mechanical properties of friction stir welded 6082 aluminium alloy. Material and Design, 28, 1124-1129

Sinclair, P. C.; Longhurst, W. R.; Cox, C. D.; Lammlein, D. H.; Alvin, M. \& Cook, G.E. (2010). Materials and manufacturing processes heated friction stir welding: an experimental and theoretical investigation into how preheating influences process 
forces heated friction stir welding: an experimental and theoretical investigation into how preheating influences process forces. Materials and Manufacturing Processes, 25, $37-41$

Su, J. Q.; Nelson, T. W.; Mishra, R. \& Mohaney, M. (2003). Microstructural investigation of friction stir welded 7050-T651 aluminium. Acta Materialia, 51, 3, 713729

Sun, Y. \& Fujii, H. (2015). Improved resistance to hydrogen embrittlement of friction stir welded high carbon steel plates. Int. J. of Hydrogen Energy, 1-11

Takehiko, W.; Hirofumi, T. \& Yanagisawa, A. (2006). Joining of aluminum alloy to steel by friction stir welding. Science and Technology of Welding and Joining, 4, 365372

Thomas, W. M.; Nicholas, E. D.; Needham, J. C.; Murch, M. G.; Templesmith, P. \& Dawes, C. J. (1991). Patent 9125978.8

Thomas, W. M.; Threadgill, P. L. \& Nicholas, E. D. (1999). Feasibility of friction stir welding steel. J. of Material Processing Technology, 178, 342-349

Ueji, R.; Fujii, H.; Cui, L.; Nishioka, A.; Kunishige, K. \& Nogi, K. (2006). Friction stir welding of ultrafine grained plain low-carbon steel formed by the martensite process. Materials Science and Engineering, 423, 324-330

Upadhyay, P. \& Reynolds, A. (2014). Effect of backing plate thermal property on friction stir welding of $25 \mathrm{~mm}$ thick AA6061. Metallurgical and Materials Transactions, 45, 2091-2100

Xu, W.; Liu, J.; Luan, G. \& Dong, C. (2009). Temperature evolution, microstructure and mechanical properties of friction stir welded thick 2219-O aluminum alloy joints. Materials \& Design, 30, 1886-1893

Xu, X.; Yang, X.; Zhou, G. \& Tong, J. (2012). Microstructures and fatigue properties of friction stir lap welds in aluminum alloy AA6061-T6. Materials \& Design, 35, 175183

Xunhong, W. \& Kuaishe, W. (2006). Microstructure and properties of friction stir buttwelded AZ31 magnesium alloy. Materials Science and Engineering, 431, 114-117 Yaduwanshi, D. K.; Bag, S. \& Pal, S. (2013). Effect of Preheating in Hybrid Friction Stir Welding of Aluminum Alloy. JMEPEG, 23, 3794-3803

Yaduwanshi, D. K.; Bag, S. \& Pal, S. (2014). Effect of Preheating in Hybrid Friction Stir Welded dissimilar joint. Design and Research Conference, 165-1-165-6

Zargar, A. O. \& Kukatpally, H. (2013).The preheating influence on welded joint mechanical properties prepared by friction stir welding aluminum alloy H20-H20. Middle-East Journal of ScientificResearch, 15, 1415-1419

Zhang, Y.; Sato, Y. S.; Kokawa, H.; Hwan, S.; Park, C. \& Hirano, S. (2008). Microstructural characteristics and mechanical properties of Ti-6Al-4V friction stir welds. Materials Science and Engineering, 485, 448-455

Zhou, L.; Zhou, W. L.; Huang, Y. X. \& Feng, J. C. (2015). Interface behavior and mechanical properties of 316L stainless steel filling friction stir welded joints. Int. J. of Adv. Manuf. Technol., 81, 577-583 